\title{
RECYCLING TECHNIQUES OF POLYOLEFINS FROM PLASTIC WASTES
}

\author{
D.S. ACHILIAS ${ }^{1, *}$ \\ E. ANTONAKOU ${ }^{2}$ \\ C. ROUPAKIAS ${ }^{1}$ \\ P. MEGALOKONOMOS ${ }^{1}$ \\ A. LAPPAS ${ }^{2}$
}

Received: 05/04/07

Accepted: 04/05/07

\author{
${ }^{1}$ Laboratory of Organic Chemical Technology \\ Department of Chemistry, Aristotle University of Thessaloniki \\ GR 54124 Thessaloniki, Greece \\ ${ }^{2}$ Laboratory of Environmental Fuels and Hydrocarbons \\ CPERI, GR 57001 Thermi, Thessaloniki, Greece
}

*to whom all correspondence should be addressed: e-mail: axilias@chem.auth.gr

\begin{abstract}
Disposing of plastic wastes to landfill is becoming undesirable due to legislation pressures, rising costs and the poor biodegradability of commonly used polymers. In addition, incineration meets with strong societal opposition. Therefore, recycling either mechanical or chemical, seems to be the only route of plastic wastes management towards sustainability. Polyolefins, mainly polyethylene (LDPE or HDPE) and polypropylene (PP) are a major type of thermoplastic used throughout the world in a wide variety of applications. In Western Europe alone approximately 22 million tones of these polymers are consumed each year, representing an amount of $56 \%$ of the total thermoplastics.

In the present investigation the recycling of LDPE, HDPE and PP was examined using two different methods: the dissolution/reprecipitation and pyrolysis. The first belongs to the mechanical recycling techniques while the second to the chemical/feedstock recycling. During the first technique the polymer can be separated and recycled using a solvent/non-solvent system. For this purpose different solvents/non-solvents were examined at different weight percent amounts and temperatures using either model polymers as raw material or commercial waste products (packaging film, bags, pipes and food retail products). At all different experimental conditions and for all samples examined the polymer recovery was always greater than $90 \%$. The quality of the recycled polymer was examined using FTIR and DSC. Furthermore, pyrolysis of LDPE, HDPE and PP was investigated with or without the use of an acid FCC catalyst. Experiments were carried out in a laboratory fixed bed reactor. The gaseous product was analyzed using GC, while the liquid with GC-MS. A small gaseous and a large liquid fraction were obtained from all polymers. Analysis of the derived gases and oils showed that pyrolysis products were hydrocarbons consisting of a series of alkanes and alkenes, with a great potential to be recycled back into the petrochemical industry as a feedstock for the production of new plastics or refined fuels.
\end{abstract}

KEYWORDS: Recycling, Polymers, LDPE, HDPE, PP, Dissolution/reprecipitation, Pyrolysis

\section{INTRODUCTION}

During last decades, the great population increase worldwide together with the need of people to adopt improved conditions of living led to a dramatical increase of the consumption of polymers (mainly plastics). Materials that appears interwoven with the consuming society where we live. Current statistics for Western Europe estimate the annual total consumption of plastic products at 48.8 million tons for 2003 corresponding to $98 \mathrm{~kg}$ per capita. The same quantity a decade before, i.e. in 1993 was approximately $64 \mathrm{~kg}$ percapita (Plastics Europe Association, 2007, Association of Plastic Manufacturers, 2007). Over 78 wt\% of this total corresponds to thermoplastics (mainly polyolefins, low density polyethylene, LDPE-17\%, high density polyethylene, HDPE-11\%, polypropylene, PP-16\%) and the remaining to thermosets (mainly epoxy resins and polyurethans). Plastics consumption in Greece in 2002 was 515.000 tons with an increasing trend from 2001 to 2002 equal to 10.9\% (Plastics Europe Association, 
2007, Association of Plastic Manufacturers, 2007). Since the duration of life of plastic wastes is very small (roughly $40 \%$ have duration of life smaller than one month), there is a vast waste stream (approximately 21.2 millions tons for 2003) that reaches each year to the final recipients creating a serious environmental problem. Despite significant advances in recent years, $61 \%$ of the plastic waste generated in W. Europe is still disposed of to landfill. The rest $39 \%$ recovered mainly with three methods. The bigger percentage was been disposed for energy recovery (4.75 million tons, percentage $22 \%)$, while $15 \%$ was mechanically recycled (3.13 million tons), with only $2 \%$ recycled chemically ( 0.35 millions tons) (Plastics Europe Association, 2007). From the total 370.000 tons of plastic wastes in Greece in 2002 the percent amount recovered and recycled was approximately 2.2\% (Association of Plastic Manufacturers, 2007).

Disposing of the waste to landfill is becoming undesirable due to legislation pressures (waste to landfill must be reduced by $35 \%$ over the period from 1995 to 2020), rising costs and the poor biodegradability of commonly used polymers. The approaches that have been proposed for recycling of waste polymers include (Scheirs, 1998; Achilias and Karayannidis, 2004): Primary recycling referring to the "in-plant" recycle of the scrap material of controlled history. Mechanical Recycling, where the polymer is separated from its associated contaminants and it is reprocessed by melt extrusion. Chemical recycling leading in total depolymerization to the monomers, or partial degradation to other secondary valuable materials. Energy recovery as an effective way to reduce the volume of organic materials by incineration. Among the recycling techniques, incineration meets with strong societal opposition and mechanical recycling can be carried out only on single-polymer waste streams. However, the most attractive method, in accordance also with the principles of sustainable development is chemical recycling also called as feedstock or tertiary recycling. According to this method waste polymers can be ether converted to original monomers or other valuable chemicals. These products are useful as feedstock for a variety of downstream industrial processes or as transportation fuel.

Polyolefins (LDPE, HDPE, PP) are a major type of thermoplastic used throughout the world in such applications as bags, toys, containers, pipes (LDPE), houswares, industrial wrappings and film, gas pipes (HDPE), film, battery cases, automotive parts, electrical components (PP). In Western Europe alone approximately 21.37 million tones of these three polymers are consumed each year (data of 2003), representing an amount of $56 \%$ of the total thermoplastics (Plastics Europe Association, 2007). Addition polymers (like polyethylene) in contrast to condensation polymers (i.e. poly(ethylene terephthalate) (PET)) can not be easily recycled by simple chemical methods (Karayannidis and Achilias, 2007). Instead, thermochemical recycling techniques like pyrolysis have been proposed as process producing a series of refined petrochemical products and particularly of a liquid fraction similar with that of commercial gasoline (Achilias and Karayannidis, 2004).

Thermal cracking of polyolefins is usually carried out either in high temperatures $\left(>700^{\circ} \mathrm{C}\right)$, to produce an olefin mixture $\left(\mathrm{C}_{1}-\mathrm{C}_{4}\right)$ and aromatic compounds (mainly benzene, toluene and xylene) or in low temperature $\left(400-500^{\circ} \mathrm{C}\right)$ (thermolysis) where three fractions are received: a high-calorific value gas, condensable hydrocarbon oil and waxes (Aguado and Serrano, 1999). In the first case the objective is to maximize the gas fraction and to receive the olefins, which could be used after separation as monomers for the reproduction of the corresponding polyolefins (Kaminski et al., 1995). Cracking in lower temperatures leaves a waxy product in the reactor that mainly consists of parafins together with a carbonized char. The gaseous fraction can be used for the supply of the energy required for the pyrolysis after burning. The liquid fraction mainly consists of linear olefins and parafins with $C_{11}-C_{14}$ carbon atoms with only traces of aromatic compounds (Aguado and Serrano, 1999). Thermal cracking of polyolefins proceeds through a random scission mechanism in four steps: initiation, depropagation, inter- or intra- molecular hydrogen transfer followed by b-scission and termination. In general, thermal cracking is more difficult in HDPE followed by LDPE and finally by PP (Uddin et al., 1997). Due to the low thermal conductivity of polymers together with the endotherm of cracking, thermal pyrolysis consumes large amounts of energy. Thus, catalytic technologies have been proposed to promote cracking at lower temperatures, 
resulting in reduced energy consumption and higher conversion rates (Manos et al., 2002). Furthermore, use of specific catalysts allows the process to be directed towards the formation of a narrower distribution of hydrocarbon products with a higher market value (Aguado and Serrano, 1999). Heterogeneous catalysis has been investigated extensively using solids with acid properties. Zeolites of the kind employed in the catalytic cracking of hydrocarbon feedstocks (Y, ZSM-5, Beta) as well as other well-known acid solids like silica-alumina, alumina and clays are being the most studied (Manos et al., 2002). Mixtures of these catalysts like SAHA/ZSM-5, MCM-41/ZSM-5 have been also used. Cracking with acid catalysts takes place through the formation of carbocations, which requires the presence of strong acidic regions. Acid strength and textural properties are the main parameters dictating the performance of acid solids in the catalytic conversion of polymers. Porosity, surface area characteristics and particle size determine to a large extent the accessibility of bulky polymeric molecules to the internal catalytic acid sites of the solids. Thus while catalyst HZSM-5 presents bigger reactivity from HMCM-41 in the cracking of HDPE and LDPE, at the decomposition of the large molecules of PP the transformation is almost the same with that of thermal cracking, because cross-section of polymer is very big in order to enter in catalysts' micropores (Aguado et al., 2004).

In the present investigation, the chemical recycling of LDPE, HDPE and PP was examined using two different methods: the traditional method of dissolution/ reprecipitation and the more challenging technique of pyrolysis. The first belongs to the mechanical recycling techniques while the second to the chemical/feedstock recycling. During the first technique the polymer can be separated and recycled using a solvent/non-solvent system (Papaspyrides et al., 1994; Poulakis and Papaspyrides, 1994). For this purpose different solvents/non-solvents were examined at different weight percent amounts and temperatures using either model polymers as raw material or commercial products (packaging film, bags, pipes, food retail products). Two solvents were chosen for the recycling process, based on the fact that plastics can be dissolved in solvents with similar values of the solubility parameter, $\delta$. These solvents were xylene $\left[\delta=8,8 \mathrm{cal}^{1 / 2} \mathrm{~cm}^{-312}\right]$ and toluene $\left[\delta=8,9 \mathrm{cal}^{1 / 2} \mathrm{~cm}^{-312}\right]$. Polyolefins represents, generally, a value of solubility parameter near to $8,0 \mathrm{cal}^{1 / 2} \mathrm{~cm}^{-312}$. Furthermore, pyrolysis of LDPE, HDPE and PP was carried out in a laboratory fixed bed reactor, with and without the use of a commercial FCC catalyst. All compounds in the gaseous and oil pyrolysis fractions were identified. Conclusions are very encouraging concerning alternative techniques of waste polymer recycling.

\section{MATERIALS AND METHODS}

\subsection{Materials}

Model polyolefins (LDPE, HDPE and PP) obtained from Aldrich and different commercial products (packaging film, bags, pipes, food retail products) made from these polymers. The solvents used (toluene, xylene, n-hexane) were reagent grade. In some pyrolysis experiments an FCC catalyst was used with the following characteristics: total surface area: $178.4 \mathrm{~m}^{2} \mathrm{~g}^{-1}$, zeolite area: $58.5 \mathrm{~m}^{2} \mathrm{~g}^{-1}$, Z/M: 0.49 and UCS: $24.26 \AA$.

\subsection{Dissolution/reprecipitation technique}

In a first approach, model LDPE, HDPE and PP were used together with different commercial products containing those polymers. Xylene and toluene were used as solvents, while nhexane as non-solvent. Some other parameters include solvent/non-solvent volume ratio: 1/3, dissolution temperatures below the boiling point for each solvent $\left(140^{\circ} \mathrm{C}\right.$ for xylene and $110^{\circ} \mathrm{C}$ for toluene) and various polymer concentrations. The experimental process comprised: the polymer $(1 \mathrm{gr})$ and the solvent $(20 \mathrm{ml})$ were added into a flask equipped with a vertical condenser and a magnetic stirrer. The system was heated for $30 \mathrm{~min}$ to the desired temperature. Then, the flask was cooled and the solution of the polymer was properly poured into the non-solvent. The polymer was re-precipitated, washed, filtrated and dried in an oven at $80^{\circ} \mathrm{C}$ for $10 \mathrm{~h}$. The recycled polymer was obtained in the form of powder or grains. 


\subsection{Measurements}

Fourier-Transform Infra-Red (FTIR). The chemical structure of the model polymers and waste plastics, before and after the recycling technique was confirmed by recording their IR spectra. The instrument used was an FTIR spectrophotometer of Perkin-Elmer, Spectrum One. The resolution of the equipment was $4 \mathrm{~cm}^{-1}$. The recorded wavenumber range was from 450 to $4000 \mathrm{~cm}^{-1}$ and 16 spectra were averaged to reduce the noise. A commercial software Spectrum v5.0.1 (Perkin Elmer LLC 1500F2429) was used to process and calculate all the data from the spectra. Thin polymeric films were used in each measurement, formed by a hydraulic press Paul-Otto Weber, at a temperature $20^{\circ} \mathrm{C}$ above the melting point of each polymer.

Differential Scanning Calorimetry (DSC). The melting temperature, Tm, of model polymers, waste plastic products, as well as the polymers produced after the recycling procedure was measured using the Pyris-1 DSC from Perkin Elmer. Samples of approximately $10 \mathrm{mg}$ were introduced into the appropriate position of the instrument and the heat released was recorded at a temperature interval 50 to $200^{\circ} \mathrm{C}$ and a scan rate of $20^{\circ} \mathrm{C} / \mathrm{min}$. The calorimeter was calibrated using indium and zinc standards.

\subsection{Pyrolysis}

All experiments took place in the Laboratory of Environmental Fuels and Hydrocarbons, situated in CPERI, Thessaloniki, Greece. The reactor (Fig. 1) was filled with $0.7 \mathrm{~g}$ of the FCC catalyst the piston was filled with the polymer $(1.5 \mathrm{~g})$. Glasswool was placed in the bottom of the reactor, the top of the piston and inside the bed in order to separate the catalyst and the polymer bed. The system was always heated in the presence of $\mathrm{N}_{2}\left(30 \mathrm{ml} \mathrm{min}^{-1}\right)$ and, by using a temperature controller the temperature of each zone of the furnace was controlled. As soon as the reaction temperatures were achieved, polymer entered the reactor and the experiment started. The time of the experiment was $17 \mathrm{~min}$ and the reaction temperature $450^{\circ} \mathrm{C}$. At the end of the experiment purging ( $30 \mathrm{~min}$ ) was performed. Both the experiment and purging were performed in the presence of $\mathrm{N}_{2}$. The liquid products were collected in a liquid bath $\left(-17^{\circ} \mathrm{C}\right)$ and quantitatively measured in a pre-weighted glass receiver. The gaseous products were collected and measured by water displacement. The amount of residue was measured by direct weighting. The liquid samples were analysed by GC/MS in a HP 5989 MS ENGINE, while the gaseous products by GC in a HP 6890, equipped with four columns and two detectors (TCD and FID). The chromatograph was standardized with gases at known concentrations as standard mixtures.

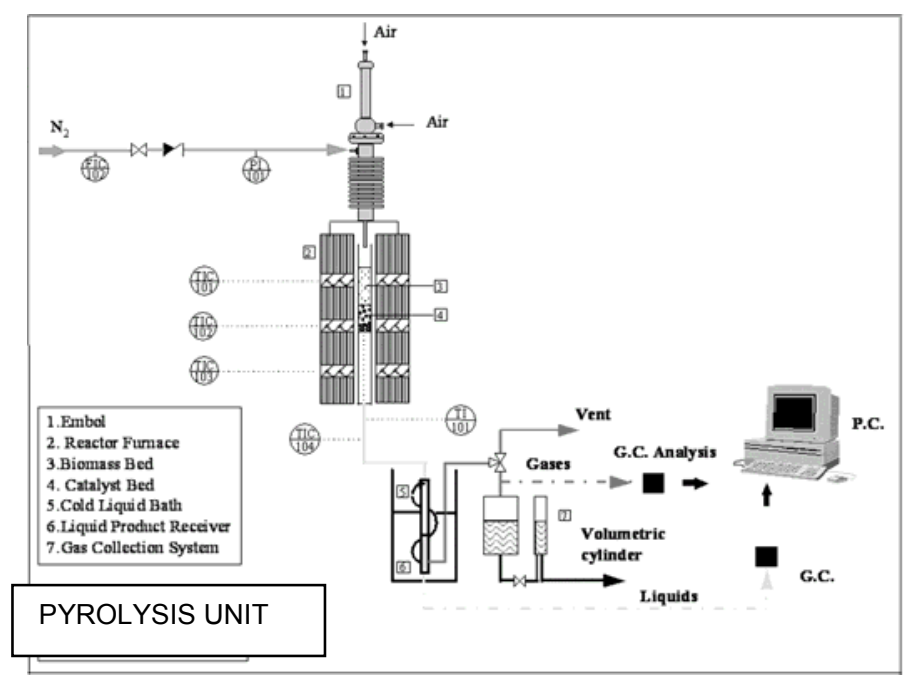

Figure 1. The fixed bed reactor system 


\section{RESULTS AND DISCUSSION}

\subsection{Recycling of polyolefins by the dissolution/reprecipitation technique}

The effect of the dissolution temperature and initial polymer concentration on the wt.- $\%$ recovery of the three model polyolefins (LDPE, HDPE, PP) is illustrated in Figures 2 and 3, respectively. It was observed that at all different experimental conditions the polymer recovery was always high. Polymer recovery was favoured by an increase in dissolution temperature and lower concentrations of polymer in solvent.

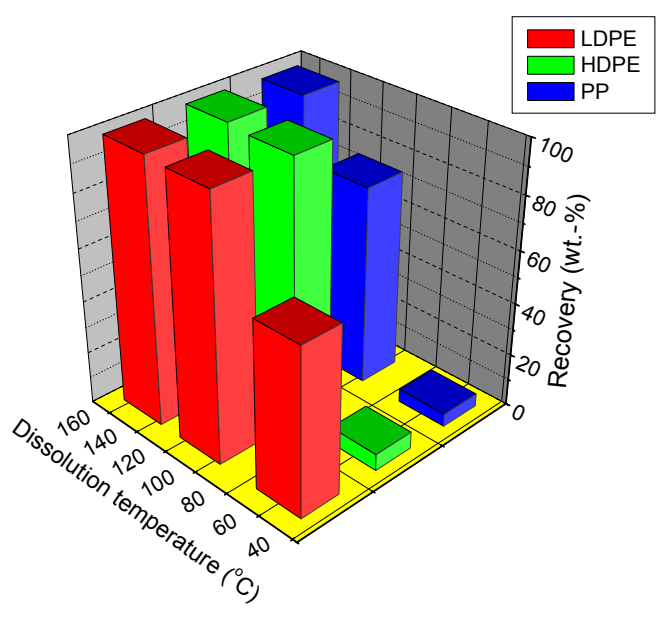

Figure 2. Effect of dissolution temperature on the $\%$ recovery of polymer from model polyolefins using xylene/n-hexane and $5 \%$ w/v sample concentration

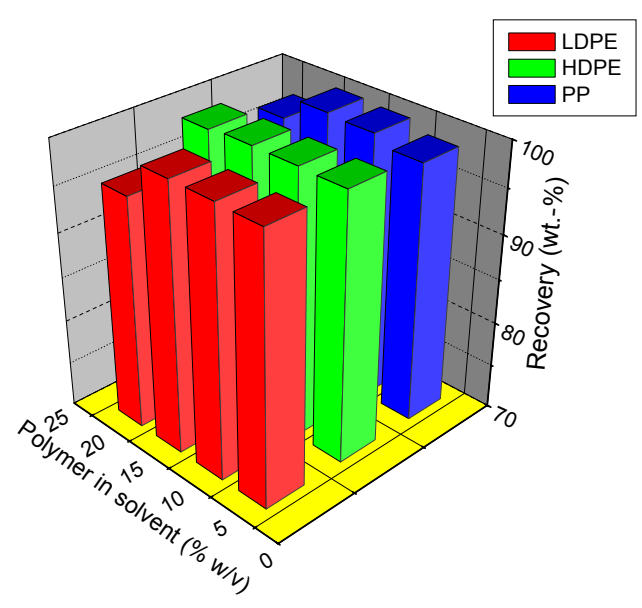

Figure 3. Effect of sample concentration on the $\%$ recovery of polymer from model polyolefins using xylene/n-hexane at $140^{\circ} \mathrm{C}$

The type of polymer used did not affect much the recovery values, while it was observed that LDPE can be recovered in high values even at low dissolution temperatures. Use of another solvent (i.e. toluene) in place of xylene did not seem to improve the recovery values. In contrast, lower amounts of polymer were recovered in some experiments. Therefore, in the following xylene was always used as a solvent.

Furthermore, the recovery of polyolefins from several waste plastic products, based on these polymers, appears in Figure 4. According to the experimental values, high polymer recoveries were measured for all waste samples examined.

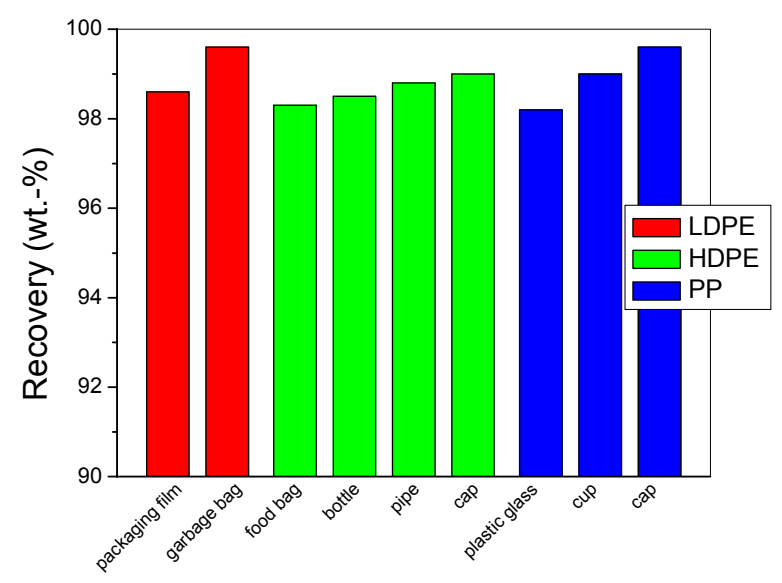

Figure 4. Recovery of polyolefins from different waste plastic products by the dissolution/reprecipitation technique using xylene/n-hexane at $140^{\circ} \mathrm{C}$ and $5 \% \mathrm{w} / \mathrm{v}$ sample concentration 
Subsequently, the quality of the product before and after the recycling technique was investigated. Indicative spectra for PP based materials are presented in Figure 5.

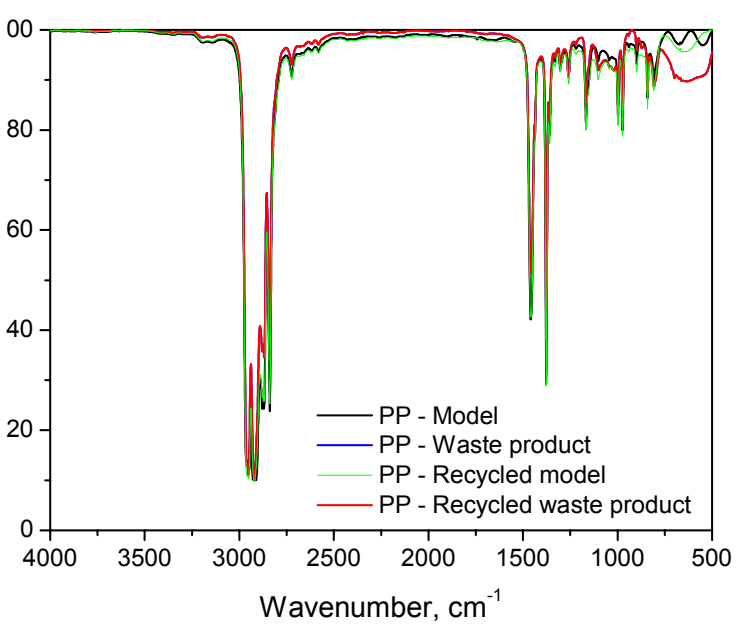

Figure 5. FT-IR spectra of PP based materials before and after recycling

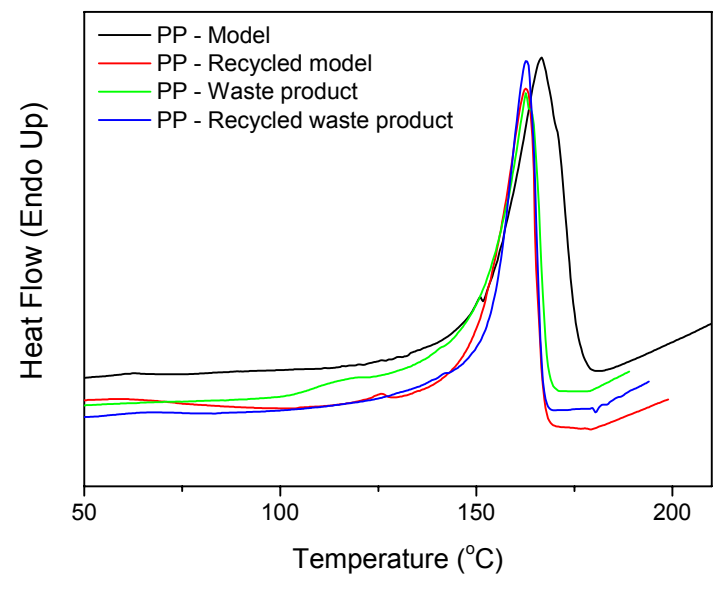

Figure 6. DSC scans of PP based materials before and after recycling

Comparing the FT-IR spectra of the solid obtained after recycling of either model polyolefins or waste products with that of the corresponding model polymer identified the polymer recovered with this technique. As it can be seen, in all cases the same peaks were recorded and all four lines almost coincide. In advance, the melting temperature of all products before and after recycling, were measured and are illustrated in Table 1. No significant difference was observed between the values measured before and after recycling for all model polymers and waste samples. However, a small difference was noticed between the values of the virgin model polymer and the waste sample based on this polymer for LDPE and HDPE. This is probably attributed to admixtures of additives in the commercial waste products, which was also observed in the melting thermograms, as broader curves (Figure 6).

Table 1. Melting temperature $\left({ }^{\circ} \mathrm{C}\right)$ of model and waste plastic products before and after the recycling technique

\begin{tabular}{lccc}
\hline Sample & Polymer \\
& LDP & HDPE & PP \\
\hline Model & 115 & 140 & 165 \\
Model - recycled & 113 & 136 & 163 \\
Waste plastic product & 120 & 127 & 163 \\
Waste plastic product - recycled & 120 & 127 & 163 \\
\hline
\end{tabular}

\subsection{Recycling of polyolefins by pyrolysis}

Thermal cracking or pyrolysis, involves the degradation of the polymeric materials by heating in the absence of oxygen (usually in a nitrogen atmosphere). During pyrolysis at increased temperatures, depending on polymer type, either end-chain, or random scission of the macromolecules occurs. In the first case (occurring in poly(methyl methacrylate)) the monomer can be produced in a large amount, while in the second, occurring mainly in polyolefins (LDPE, HDPE, PP) the amount of monomer produced is very low. A review on the 
current trends in polyolefin chemical recycling has appeared in literature (Achilias et al., 2006).

In this investigation, results are presented for the pyrolysis of model LDPE, HDPE and PP with or without the use of an acid FCC catalyst. The values measured for the product yield appear in Table 2.

Table 2. Experimental conditions and product yield from the thermal and catalytic pyrolysis of LDPE, HDPE and PP.

\begin{tabular}{|c|c|c|c|c|c|}
\hline Polymer & $\begin{array}{c}\text { Temperature } \\
\left({ }^{\circ} \mathrm{C}\right)\end{array}$ & Catalyst & Gas $\%$ (wt.- & $\begin{array}{l}\text { Liquid } \\
\%)\end{array}$ & $\begin{array}{c}\text { Residue } \\
\text { (wt.-\%) }\end{array}$ \\
\hline LDPE & 450 & - & 1.4 & 22.2 & 76.4 \\
\hline HDPE & 450 & - & 1.7 & 21.6 & 76.7 \\
\hline PP & 450 & - & 4.1 & 49.3 & 46.6 \\
\hline LDPE & 450 & FCC & 0.5 & 46.6 & 52.9 \\
\hline HDPE & 450 & FCC & 0.5 & 38.5 & 61.0 \\
\hline PP & 450 & FCC & 6.2 & 67.3 & 26.5 \\
\hline
\end{tabular}

It is seen that since pyrolysis temperature is rather low a small gaseous fraction was obtained from all polymers. The presence of catalyst lead to increased amounts of the liquid fraction accompanied by decreased gaseous fraction and residue. It was also observed that the relative amounts of gas and liquid fraction are very much dependent on the type of polymer used. Thus, higher decomposition was observed in PP, followed by LDPE and finally HDPE. It seems that less crystalline or more branched polymers are less stable in thermal degradation. However, the type of products formed is not so much dependent on the polymer type, as it is illustrated in Tables 3 and 4 for the gaseous and liquid composition, respectively.

Table 3. Composition of the gaseous fraction from the thermal and catalytic pyrolysis of LDPE, HDPE and PP (wt \% on polymer)

\begin{tabular}{lcccccc}
\hline & & \multicolumn{5}{c}{ Polymer } \\
Catalyst & LDPE & HDPE & PP & LDPE & HDPE & PP \\
\hline $\mathrm{H}_{2}$ & - & - & - & FCC & FCC & FCC \\
$\mathrm{CO}_{2}$ & 0.007 & 0.002 & 0.030 & 0.001 & 0.001 & 0.002 \\
$\mathrm{CO}$ & 0.000 & 0.000 & 0.000 & 0.000 & 0.000 & 0.000 \\
$\mathrm{CH}_{4}$ & 0.000 & 0.000 & 0.000 & 0.000 & 0.000 & 0.000 \\
$\mathrm{C}_{2} \mathrm{H}_{6}$ & 0.017 & 0.004 & 0.085 & 0.002 & 0.001 & 0.030 \\
$\mathrm{C}_{2} \mathrm{H}_{4}$ & 0.047 & 0.009 & 0.115 & 0.003 & 0.002 & 0.072 \\
$\mathrm{C}_{3} \mathrm{H}_{8}$ & 0.038 & 0.011 & 0.224 & 0.004 & 0.002 & 0.026 \\
$\mathrm{C}_{3} \mathrm{H}_{6}$ & 0.106 & 0.025 & 0.066 & 0.011 & 0.007 & 0.060 \\
$\mathrm{nC}_{4} \mathrm{H}_{10}$ & 0.111 & 0.130 & 0.645 & 0.068 & 0.058 & 1.101 \\
$\mathrm{nC}_{5}$ & 0.310 & 0.441 & 0.445 & 0.190 & 0.176 & 2.565 \\
$\mathrm{iC}_{5}$ & 0.167 & 0.366 & 0.672 & 0.050 & 0.057 & 1.003 \\
$\mathrm{C}_{6}(+)$ & 0.234 & 0.254 & 1.054 & 0.080 & 0.119 & 0.664 \\
Total & 0.311 & 0.465 & 0.775 & 0.047 & 0.062 & 0.717 \\
\hline
\end{tabular}


As it can be seen from Table 3, concerning the composition of the gaseous fraction, in all polymers examined a series of alkanes and alkenes are produced from $\mathrm{C}_{1}-\mathrm{C}_{5}$ with the greater percentage for all samples observed at $\mathrm{C}_{4}$. It seems that after the initial removal of short or long branches in the macromolecular chain the mechanism of degradation remains the same independent of the polyethylene type. Cracking of all polyolefins also did not lead to the production of $\mathrm{CO}$ or $\mathrm{CO}_{2}$, since in the polymer molecules there exist not any oxygen atoms.

Finally, the compounds identified in the liquid fraction from pyrolysis appear in Table 4. A mixture of hydrocarbons was determined for all three samples in the region of commercial fuels. The main part consisted of aliphatic compounds (normal and iso alkanes and alkenes), with only a small proportion of aromatic substances. This again is due to the rather low pyrolysis temperature. Furthermore, the existence of the catalyst increased the amount of hydrocarbons in the region $\mathrm{C}_{7}$ to $\mathrm{C}_{13}$ and decreased the higher than $\mathrm{C}_{15}$ compounds. This fact, in combination with the formation of some aromatic compounds leads to the conclusion that the existence of the FCC catalyst leads to a production of a probable better type of fuel in the liquid pyrolysis fraction, when it is used.

A typical GC-MS diagram for the liquid fraction taken from LDPE pyrolysis is illustrated in Figure 7. Characteristic lines for hydrocarbons with different number of carbon atoms appear. Also it is clear that these are not single lines, meaning the existence of alkanes, alkenes and alkadienes having the same number of carbon atoms.

Table 4. Compounds identified in the liquid fraction of the thermal and catalytic pyrolysis of LDPE, HDPE and PP (wt.-\% on liquid fraction)

\begin{tabular}{lcccccc}
\hline Polymer & LDPE & HDPE & PP & LDPE & HDPE & PP \\
Catalyst & FCC & FCC & FCC & - & - & - \\
\hline${\mathrm{i}-\mathrm{C}_{6}}$ & - & 2.9 & 1.6 & 0.1 & - & 2.3 \\
$\mathrm{C}_{7}$ & 0.8 & 1.9 & - & - & - & - \\
$\mathrm{i}-\mathrm{C}_{7}$ & 1.4 & 2.9 & 1.0 & 0.6 & 0.4 & 2.2 \\
$\mathrm{C}_{8}{ }^{2}$ & 3.9 & 2.0 & 3.4 & 0.8 & 0.5 & - \\
$\mathrm{i}-\mathrm{C}_{8}$ & 0.3 & 1.8 & 2.1 & 1.0 & 0.6 & 0.4 \\
$\mathrm{C}_{9}$ & 1.4 & 4.3 & 2.6 & 0.8 & 0.4 & 2.6 \\
$\mathrm{C}_{10}$ & 8.0 & 5.7 & 5.2 & 1.9 & 3.0 & 4.6 \\
$\mathrm{C}_{11}$ & 6.4 & 2.5 & 4.1 & 3.2 & 3.9 & 5.3 \\
$\mathrm{C}_{12}$ & 8.1 & 4.7 & 9.1 & 3.4 & 5.9 & 2.2 \\
$\mathrm{C}_{13}$ & 3.7 & 2.9 & 1.8 & 1.4 & 1.8 & - \\
$\mathrm{C}_{14}$ & 7.9 & 6.1 & 6.3 & 3.7 & 9.7 & 0.9 \\
$\mathrm{C}_{15}(+)$ & 38.4 & 36.5 & 37.7 & 59.1 & 50.1 & 48.6 \\
Naphthenes & 7.1 & 21.4 & 7.9 & 3.9 & 7.7 & 19.2 \\
Aromatics & 2.9 & 0.8 & 0.6 & - & - & 0.1 \\
Other & 9.7 & 3.6 & 16.6 & 20.1 & 16.0 & 11.6 \\
compounds & & & & & & \\
\hline
\end{tabular}

\section{CONCLUSIONS}

The recycling of LDPE, HDPE and PP was examined by both a dissolution/reprecipitation technique and pyrolysis. The first leads to high recovery of polymer with the disadvantage of using large amounts of organic solvents. Pure polymer from waste plastics can be easily recovered with this technique. Pyrolysis seems to be the most promising technique resulting in an oil and gaseous product. Both fractions have a mainly aliphatic composition consisting of a series of alkanes and alkenes of different carbon number with a great potential to be recycled back into the petrochemical industry as a feedstock for the production of new 
plastics or refined fuels. The addition of an FCC catalyst improved the quality of the liquid fraction. This research is continued further by examining pyrolysis of polyolefin mixtures, as well as commercial waste products based on these polymers.

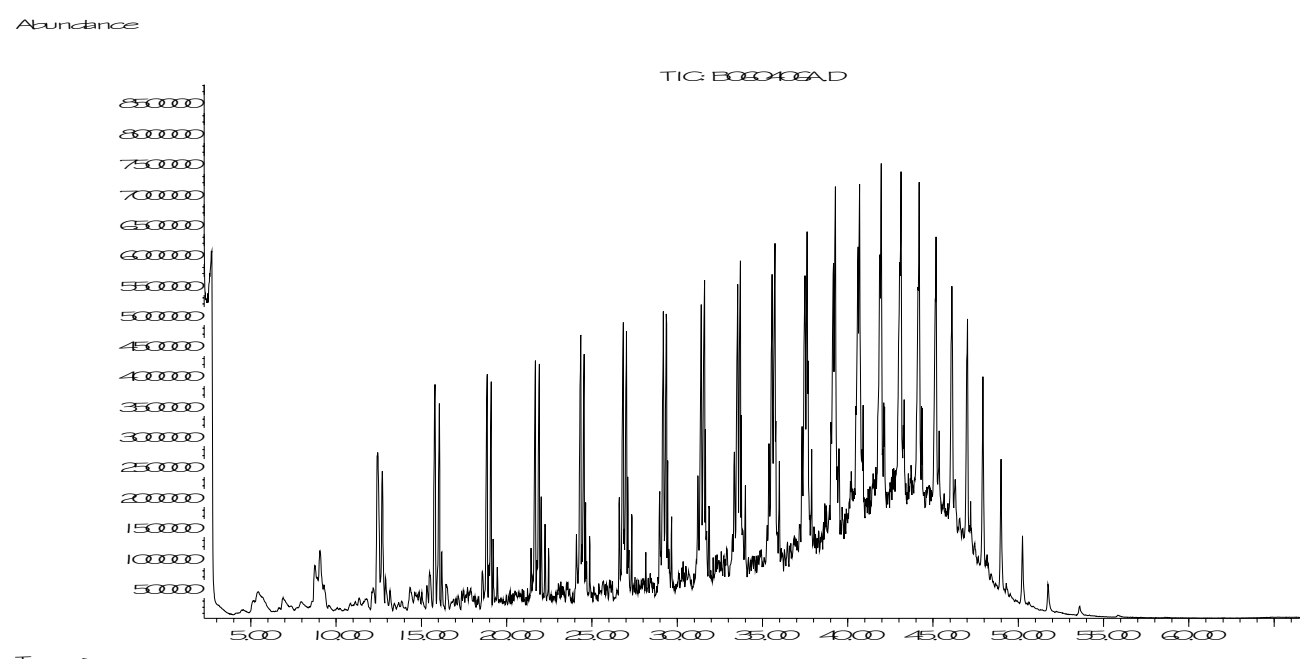

Figure 7. GC-MS chromatogram of the liquid fraction obtained from LDPE pyrolysis

\section{Aknowledgements}

This work was funded by the E.K.T./E.П.E.A.E.K. II in the framework of the research program PYTHAGORAS II, Metro 2.6 (Code 80922).

\section{REFERENCES}

Achilias D.S. and Karayannidis G.P., (2004), The chemical recycling of PET in the framework of sustainable development, Water, Air \& Soil Pollution: Focus, 4, 385.

Achilias D.S., Megalokonomos P. and Karayannidis G.P., (2006), Current trends in chemical recycling of polyolefins, J. Environ. Prot. Ecology, 7, 407.

Aguado J. and Serrano D.P., (1999), Feedstock Recycling of Plastic Wastes, The Royal Society of Chemistry, (Series Editor J.H. Clark), Cambridge.

Aguado J., Serrano D., Escola J., Rodriguez, J. and San Miguel G., (2004), An investigation into the catalytic degradation of LDPE using Py-GC/MS, J. Anal. Appl. Pyrol., 73, 79.

Assosiation of Plastic Manufacturers (2007) www.apme.org (March 2007)

Kaminski W., Schlesselmann B. and Simon C., (1995), Olefins from polyolefins and mixed plastics by pyrolysis, J. Anal. Appl. Pyrol., 32, 19.

Karayannidis G.P. and Achilias D.S., (2007), Chemical recycling of poly(ethylene terephthalate), Macromol. Mater. Eng., 292, 128.

Manos, G., Yusof, I., Gangas, N.H. and Papayannakos, N. (2002), Tertiary recycling of polyethylene to hydrocarbon fuel by catalytic cracking over aluminum pillared clays, , Energy \& Fuels, 16, 485.

Papaspyrides C.D., Poulakis, J.G. and Varelides P.C., (1994), A model recycling process for LDPE, Res. Conserv. Recycl., 12, 177.

Plastics Europe Association (2007) www.plasticseurope.org (March 2007)

Poulakis J.G. and Papaspyrides, C.D., (1995), The dissolution/reprecipitation technique applied on HDPE: Model recycling experiments, Adv. Polym. Technol., 14, 237.

Scheirs J., (1998), Polymer Recycling, J. Wiley \& Sons, W. Sussex.

Uddin A., Koizumi K. and Sakata Y., (1997), Thermal and catalytic degradation of structurally different types of polyethylene into fuel oil, Polym. Degrad. Stab., 56, 37. 